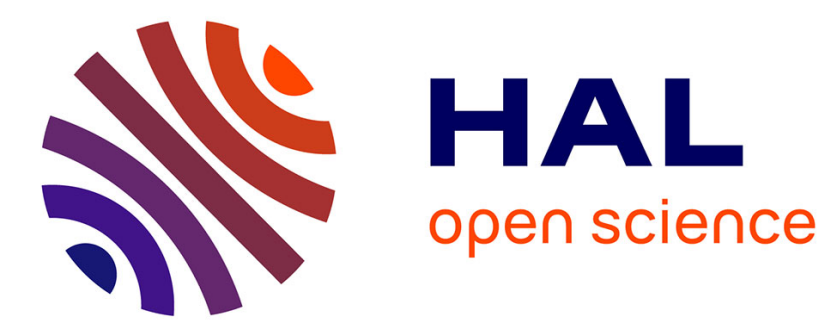

\title{
Dopant diffusion during amorphous silicon crystallization
}

\author{
A. Portavoce, R Simola, D. Mangelinck, J. Bernardini, P. Fornara
}

\section{To cite this version:}

A. Portavoce, R Simola, D. Mangelinck, J. Bernardini, P. Fornara. Dopant diffusion during amorphous silicon crystallization. Defect and Diffusion Forum, 2007, 264, pp.33-38. hal-02406682

\section{HAL Id: hal-02406682 \\ https://hal-amu.archives-ouvertes.fr/hal-02406682}

Submitted on 12 Dec 2019

HAL is a multi-disciplinary open access archive for the deposit and dissemination of scientific research documents, whether they are published or not. The documents may come from teaching and research institutions in France or abroad, or from public or private research centers.
L'archive ouverte pluridisciplinaire HAL, est destinée au dépôt et à la diffusion de documents scientifiques de niveau recherche, publiés ou non, émanant des établissements d'enseignement et de recherche français ou étrangers, des laboratoires publics ou privés. 


\title{
Dopant diffusion during amorphous silicon crystallization
}

\author{
A. Portavoce ${ }^{1, a}$, R. Simola $a^{1,2, b}$, D. Mangelinck ${ }^{1, c}$, J. Bernardini ${ }^{1, d}$ \\ and P. Fornara ${ }^{2, e}$ \\ 1'L2MP CNRS UMR 6137, Université Paul Cézanne, Case 142, 13397 Marseille Cedex 20, France \\ ${ }^{2}$ ST Microelectronics, 77 Avenue Olivier Perroy, 13790 Rousset, France \\ aalain.portavoce@l2mp.fr, 'roberto.simola@l2mp.fr, 'dominique.mangelinck@l2mp.fr, \\ jean.bernardini@|2mp.fr, ${ }^{\mathrm{e}}$ pascal.fornara@st.com
}

Keywords: Silicon crystallization, boron, phosphorus, diffusion, polycrystalline silicon, dopant interactions.

\begin{abstract}
We have investigated the redistribution of B during the crystallization of an amorphous Si layer homogeneously doped with $\mathrm{P}$. The redistribution of B only occurs for concentrations lower than $2 \times 10^{20}$ at $\mathrm{cm}^{-3}$. Crystallization leads to a non "Fickian" redistribution, allowing an abrupt interface between the regions doped and undoped with B. Once the crystallization is ended, B diffuses through the layer in the type $B$ regime with a coefficient which is in agreement with the literature data for diffusion in polycrystalline Si. Although the P distribution is homogeneous in the entire layer, for a temperature as high as $755{ }^{\circ} \mathrm{C}, \mathrm{P}$ diffuses towards the region the most concentrated in $\mathrm{B}$. The $\mathrm{B}$ and $\mathrm{P}$ interactions are interpreted as chemical interactions.
\end{abstract}

\section{Introduction}

The redistribution of dopants in silicon-based structures is of crucial importance for the fabrication of microelectronic devices. Doped polycrystalline silicon is used for the fabrication of gates in transistors and memories. In the microelectronic industry, these layers are usually produced in two steps: an amorphous $\mathrm{Si}$ film is first deposited by chemical vapor deposition on $\mathrm{SiO}_{2}$ and then crystallized during a heat treatment. In order to control the doping of such layers, it is thus important to understand the diffusion behavior of dopants in amorphous and polycrystalline Si. Furthermore, the actual microelectronic technology requires the ability to create ultra-shallow junctions with a depth about tens of nanometers. A promising technique consisting of implanting the dopants in amorphized Si before re-crystallization has been found to provide interesting sheet resistances and junction depths [1]. In order to create $p n$-junctions in polycrystalline $\mathrm{Si}$ (poly-Si) using this technique, the study of the redistribution of the two dopants ( $p$ - and $n$-type) before, during, and after Si crystallization is then of major importance.

Phosphorus (P) atoms ( $n$-type dopant) and boron (B) atoms ( $p$-type dopant) are commonly used to create $p n$-junctions in the microelectronic Si technology. In this article, we present a preliminary investigation of the redistribution of $\mathrm{B}$ and $\mathrm{P}$ during the crystallization of an amorphous $\mathrm{Si}$ nanolayer. The B redistribution is found to occur only for concentrations lower than $2 \times 10^{20}$ at $\mathrm{cm}^{-3}$. The redistribution mechanisms before the complete crystallization of the Si layer lead to a concentration profile which cannot result from simple "Fickian" diffusion. Once the Si layer is entirely polycrystalline, $\mathrm{B}$ diffuses in the type $B$ regime, with a coefficient which is in agreement with the literature. At low temperatures $\mathrm{P}$ is immobile, but at a temperature as high as $755^{\circ} \mathrm{C}$, it is found to diffuse towards the region the most concentrated in B.

\section{Experimental}

The sample was made from a $\mathrm{Si}(001)$ wafer where a $12 \mathrm{~nm}$ thick $\mathrm{SiO}_{2}$ layer was thermally grown on the surface before the deposition of a $100 \mathrm{~nm}$ thick amorphous $\mathrm{Si}(\mathrm{a}-\mathrm{Si})$ layer by low pressure chemical vapor deposition (LPCVD) at $530{ }^{\circ} \mathrm{C}$. This last layer was homogeneously doped with $\mathrm{P}$ atoms in situ, thanks to the simultaneous injection of phosphine and silane gases in the growth 
chamber. The obtained phosphorus doping level was $\sim 7 \times 10^{19}$ at $\mathrm{cm}^{-3}$. After the LPCVD growth, the sample was implanted with $\mathrm{B}^{+}$ions with an energy of $7 \mathrm{keV}$. The total dose of $\mathrm{B}$ atoms implanted was $\sim 3.5 \times 10^{15}$ at $\mathrm{cm}^{-2}$. The sample was then cut in several pieces. One piece was kept as a reference and the others were annealed at different temperatures $\left(585 \leq \mathrm{T} \leq 800{ }^{\circ} \mathrm{C}\right)$ for different times ( $\sim 1$ to 50 hours). The thermal treatments were performed in a furnace under vacuum with a pressure during annealing of about $\sim 10^{-6}$ Torr. The furnace temperature was measured in situ using a thermocouple located at $\sim 0.5$ millimeters from the samples. Transmission electron microscopy, X-ray diffraction and atomic force microscopy measurements showed that after annealing the Si layer initially deposited by LPCVD was polycrystalline in all the samples. The average lateral size of the Si grains was found to be about $40 \mathrm{~nm}$. Secondary ion mass spectroscopy (SIMS) was used in order to measure the $\mathrm{B}$ and the $\mathrm{P}$ concentration profiles versus the depth in the samples. The $\mathrm{B}$ profiles were measured under vacuum using a primary ion beam of $\mathrm{O}_{2}{ }^{+}$ions with an energy of $3 \mathrm{keV}$ and an incident angle of $45^{\circ}$. The $\mathrm{P}$ profiles were measured with the same primary ion beam but under oxygen ambient (oxygen leak) and an incident angle of $25.2^{\circ}$.

\section{Results and Discussion}

Boron Diffusion. Figure 1 presents the SIMS profile of B measured after implantation (a-Si) as well as other B concentration profiles measured after different thermal treatments following the implantation (poly-Si). After annealing at $585{ }^{\circ} \mathrm{C}$ for $1 \mathrm{~h}$, the $\mathrm{B}$ composition profile has already significantly changed compared to the as-implanted profile. While the $\mathrm{B}$ composition is found quasi-unchanged by the thermal treatment for a depth lower than $\sim 55 \mathrm{~nm}$, a shoulder has appeared for a depth between $\sim 55$ and $75 \mathrm{~nm}$. One can note that the slope of the profile after the shoulder is steeper than the slope of the end of the as-implanted profile (on its right side). This type of redistribution does not correspond to a "Fickian" behavior, considering the as-implanted profile as the initial distribution, only a diffusion model with a coefficient of diffusion varying with time (or concentration) could reproduce the experimental profile obtained after annealing at $585^{\circ} \mathrm{C}$ for $1 \mathrm{~h}$.

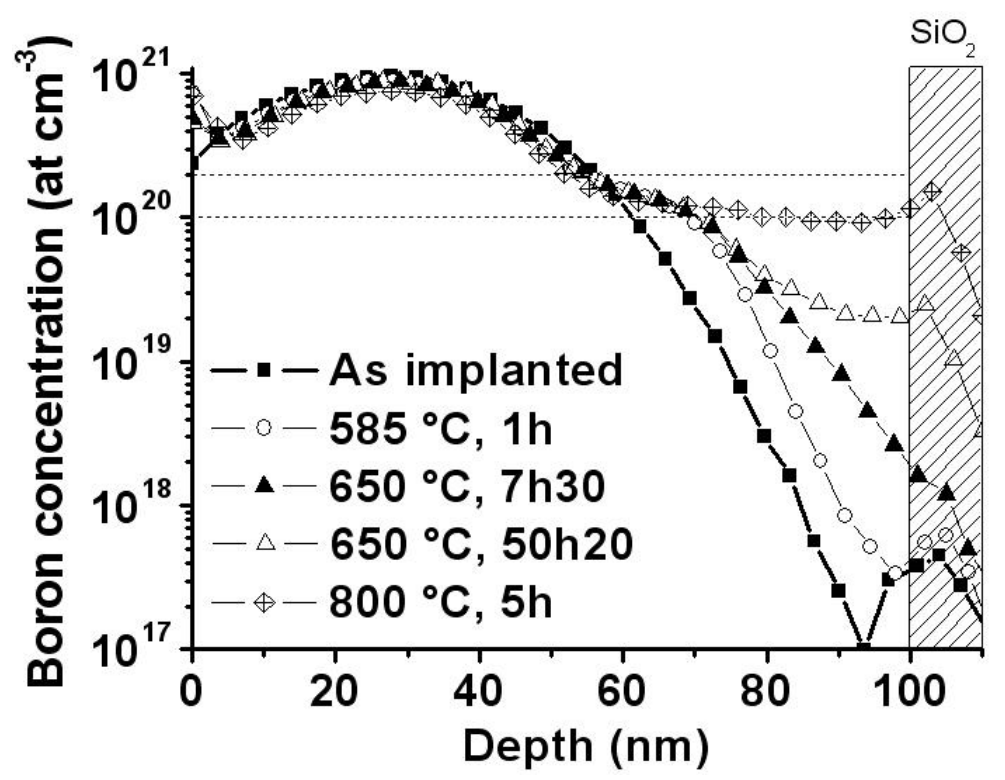

Fig. 1. B concentration profiles measured by SIMS in the sample after implantation (!); after implantation and annealing at $585^{\circ} \mathrm{C}$ for $1 \mathrm{~h}(\mathbf{O})$, at $650{ }^{\circ} \mathrm{C}$ for $7 \mathrm{~h} 30$ $\min (7)$, at $650{ }^{\circ} \mathrm{C}$ for $50 \mathrm{~h} 20 \mathrm{~min}(8)$ and at $800{ }^{\circ} \mathrm{C}$ for $5 \mathrm{~h}(\mathbf{O})$.

However, it is important to consider that in our case the dopant redistribution during annealing is not driven only by a simple diffusion process. Indeed, several steps can be discerned during annealing. First, before the crystallization starts, the dopants can diffuse in amorphous Si. Then after the nucleation and during the Si grain growth, the atoms diffuse in an inhomogeneous matrix which is made of growing $\mathrm{Si}$ grains, decreasing amorphous regions and rising grain boundaries. Finally at the end of the crystallization, the dopants are diffusing in a poly-Si matrix. Only few works have been focused so far on dopant diffusion in a-Si [2-4] and in poly-Si [5-6]. While the Arrhenius behavior of the $\mathrm{B}$ diffusion coefficient is not explicitly known in a-Si, it has already been 
studied in poly-Si. According to [6] (B diffusion coefficient measured using SIMS for temperatures between 800 and $900{ }^{\circ} \mathrm{C}$ ) the diffusion length $(\sqrt{D t})$ of $\mathrm{B}$ for annealing at $585{ }^{\circ} \mathrm{C}$ during $1 \mathrm{~h}$ should be about $\sim 6 \mathrm{~nm}$. This is significantly lower than the actual distance the $\mathrm{B}$ atoms have covered in our experiments, as the width of the shoulder on the SIMS profile is about $20 \mathrm{~nm}$. This confirms that the displacement of B is neither principally due to grain boundary diffusion nor due to in-grain diffusion. This means that either the diffusion of $\mathrm{B}$ is higher in a-Si or that another phenomenon than diffusion occurs during the heat treatment. The SIMS profile shows that B atoms have moved only for a composition lower than $\sim 2 \times 10^{20}$ at $\mathrm{cm}^{-3}$. It is interesting to remark that this doping level is higher than the usually expected solubility limit $\left(\mathrm{S}_{\mathrm{L}}\right)$ of $\mathrm{B}\left(\sim 2 \times 10^{18} \mathrm{at} \mathrm{cm}^{-3}\right.$ at $700{ }^{\circ} \mathrm{C}$ [7]) in crystalline $\mathrm{Si}$ (c-Si), but corresponds to the B solubility limit experimentally observed in Si after re-crystallization [8]. Assuming that the solubility limit of B is lower in c-Si than in a-Si (it has been shown that B is still mobile in a-Si for concentrations as high as $2 \times 10^{20}$ at $\mathrm{cm}^{-3}[4]$ ), one has to consider that at the interface c-Si / a-Si the dopant can be rejected from the grain to the amorphous regions (partition phenomenon) without involving diffusion.

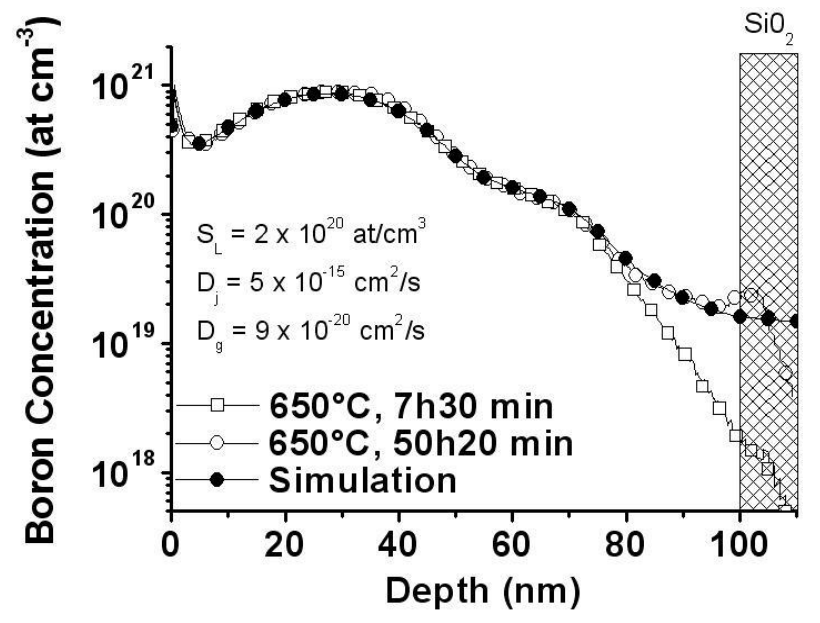

Fig. 2. B composition profiles versus depth: measured by SIMS after annealing at $650{ }^{\circ} \mathrm{C}$ for $7 \mathrm{~h}$ $30 \mathrm{~min}(\mathbf{O})$, measured by SIMS after annealing at $650{ }^{\circ} \mathrm{C}$ for $50 \mathrm{~h} 20 \mathrm{~min}(\mathbf{O})$ and simulated (,).

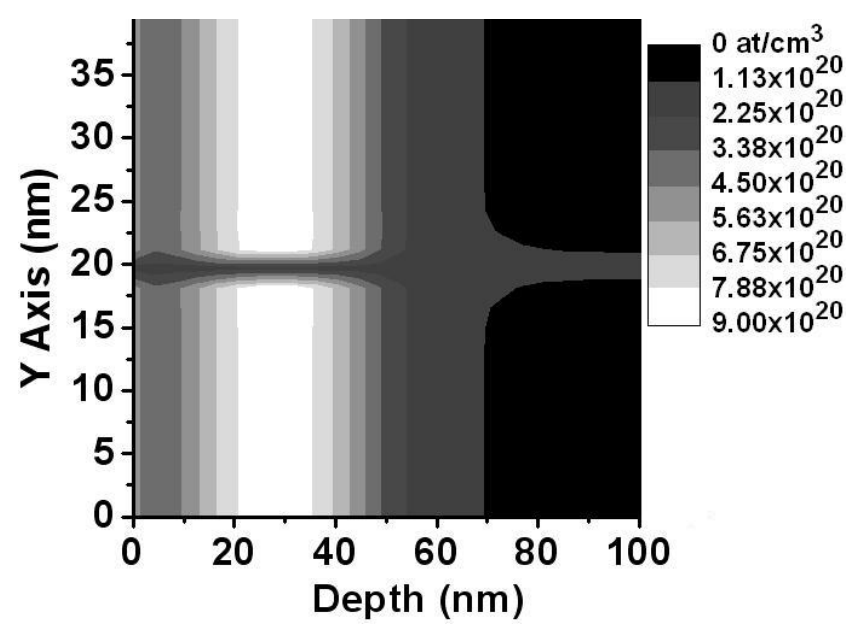

Fig. 3. Two dimensional representation of the $\mathrm{B}$ distribution $\left(\right.$ at $\left.\mathrm{cm}^{-3}\right)$ at the end of the simulation that allowed the extraction of the B diffusivity (Fig. 2). The model is composed of one grain boundary (in the middle) between two half of a grain.

If we compare the profile measured after annealing at $585^{\circ} \mathrm{C}$ for $1 \mathrm{~h}$ with the one measured after annealing at $650{ }^{\circ} \mathrm{C}$ for $7 \mathrm{~h} 30 \mathrm{~min}$, we can notice that for a depth lower than $\sim 75 \mathrm{~nm}$ the two profiles are almost superimposed. The shoulder noticed in the profile at $585{ }^{\circ} \mathrm{C}$ is unchanged in the profile at $650{ }^{\circ} \mathrm{C}$. B atoms have further diffused at $650{ }^{\circ} \mathrm{C}$, but only for compositions lower than $2 \times$ $10^{20}$ at $\mathrm{cm}^{-3}$ (the solubility limit). As the sample is already totally crystallized after annealing for $1 \mathrm{~h}$ at $585{ }^{\circ} \mathrm{C}$, the diffusion observed in the profile at $650{ }^{\circ} \mathrm{C}$ mainly occurs once the Si layer is polycrystalline. The same observations can be made by comparing the profile measured after annealing at $650{ }^{\circ} \mathrm{C}$ for $7 \mathrm{~h} 30 \mathrm{~min}$ and the profiles obtained after annealing at higher temperature or for a longer time. This means that the profile observed after the annealing at $585{ }^{\circ} \mathrm{C}$ for $1 \mathrm{~h}$ results mainly from the crystallization step, the diffusion in poly-Si being negligible. The shape of this profile can be due to both the diffusion in a-Si and/or the partition phenomenon. After the crystallization, B atoms diffuse in a poly-Si layer until they reach a uniform concentration (a plateau on the right side of the profile) which is close to the solubility limit of B in re-crystallized c-Si (Fig. 1).

In order to support our interpretation, the coefficient of diffusion of $\mathrm{B}$ at $650{ }^{\circ} \mathrm{C}$ in our poly-Si layer has been extracted and compared to the literature data. Numeric simulations were performed using the profile measured after annealing at $650{ }^{\circ} \mathrm{C}$ for $7 \mathrm{~h} 30 \mathrm{~min}$ as initial distribution, and the profile measured after heating at $650{ }^{\circ} \mathrm{C}$ for $50 \mathrm{~h} 20 \mathrm{~min}$ as final distribution. It should be stressed 
that the end of the SIMS profile (on the right side) does not correspond exactly to the real shape of the B distribution, as during SIMS measurements some B atoms are pushed deeper in the bulk because of the incident ion beam bombardment [9]. This effect is a well known SIMS artifact that can lead to some error (that is difficult to estimate) in the extracted diffusion coefficient.

The simulations show that the final diffusion profile cannot be fitted using a single effective coefficient of diffusion in the model. Thus, the $\mathrm{B}$ diffusion in the poly-Si layer is neither of type $A$ nor of type $C$ at $650{ }^{\circ} \mathrm{C}$ [10]. In consequence, the model of Fisher [11] has been used in order to simulate a diffusion of type $B$. The diffusion has been simulated by finite elements considering atom fluxes in the two directions: along the depth (diffusion in the grain and in the grain boundary) and along the direction normal to the depth direction (diffusion between the grain and the boundary). The grain size and the width of the boundary were taken to be equal to 40 and $0.5 \mathrm{~nm}$, respectively. No segregation was taken into account between the grain and the boundary. The solubility limit in c-Si was chosen to be equal to $2 \times 10^{20} \mathrm{at} \mathrm{cm}^{-3}$. Two types of simulations were performed: for the first one, the $\mathrm{B}$ clusters formed for concentrations higher than $2 \times 10^{20} \mathrm{at} \mathrm{cm}^{-3}$ could dissolve during diffusion; for the second one, the B clusters could not be dissolved during the diffusion. The second type of simulation was found to more accurately reproduce the experimental profile. It is important to remark that despite the fact that two coefficients (the diffusion coefficients in the grain and in the boundary, respectively $\mathrm{D}_{\mathrm{g}}$ and $\mathrm{D}_{\mathrm{j}}$ ) have to be adjusted in order to simulate only one profile, there is only one set of coefficients (only one solution) that can reproduce the shape of a specific profile. This is due to the fact that $\mathrm{D}_{\mathrm{g}}$ and $\mathrm{D}_{\mathrm{j}}$ influence differently the profile shape.

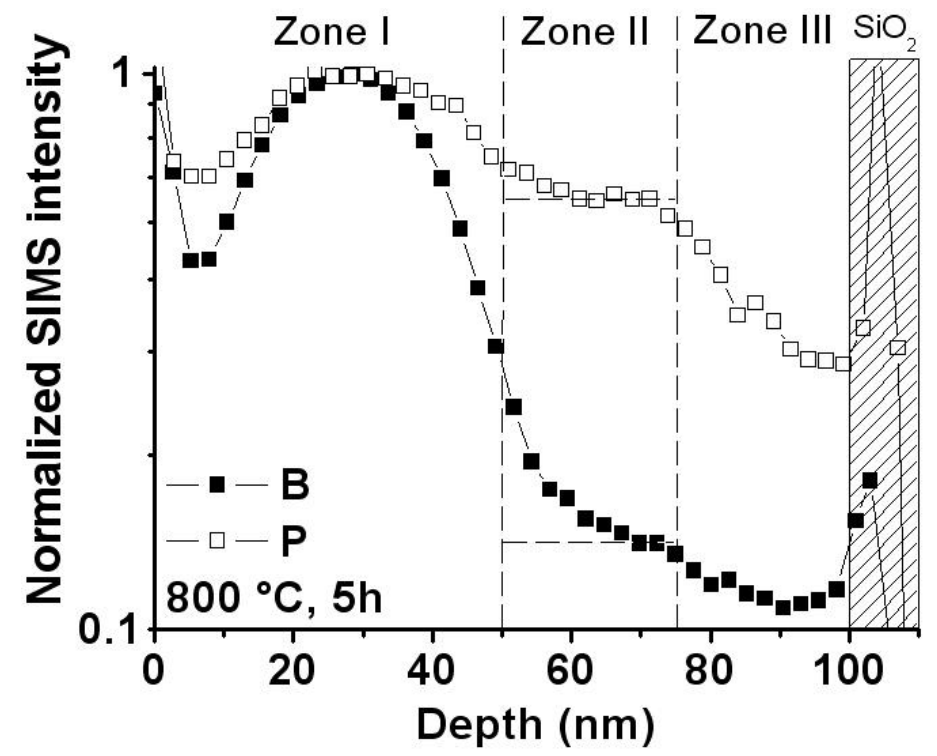

Fig. 4. SIMS profiles of $B(!)$ and $P$ (O) measured in the sample after annealing at $800{ }^{\circ} \mathrm{C}$ for 5 hours. The maximum concentration measured for $\mathrm{B}$ and $\mathrm{P}$ has been normalized to 1.

Figure 2 presents the two experimental profiles used as initial and final B distribution as well as the best fit of the final profile obtained by simulation. This fit corresponds to $D_{g}=9 \times 10^{-20} \mathrm{~cm}^{2} \mathrm{~s}^{-1}$ and $D_{j}=5 \times 10^{-15} \mathrm{~cm}^{2} \mathrm{~s}^{-1}$. These values for the coefficient of diffusion in the grain and in the grain boundary are in good agreement with the values extrapolated from the data reported in the literature. For example, from the Arrhenius description of the B diffusion coefficient given in [12] (diffusivity measured for $875 \leq \mathrm{T} \leq 1230{ }^{\circ} \mathrm{C}$ ) and [13] (diffusivity measured for $810 \leq \mathrm{T} \leq$ $\left.1050{ }^{\circ} \mathrm{C}\right), \mathrm{D}_{\mathrm{g}}$ is found to be equal to $9.8 \times 10^{-20} \mathrm{~cm}^{2} \mathrm{~s}^{-1}$ and to $5.6 \times 10^{-19} \mathrm{~cm}^{2} \mathrm{~s}^{-1}$ at $650{ }^{\circ} \mathrm{C}$, respectively. From [6] (diffusivity measured for $800 \leq \mathrm{T} \leq 900^{\circ} \mathrm{C}$ ) and [5] (diffusivity measured for $\left.900 \leq \mathrm{T} \leq 1100^{\circ} \mathrm{C}\right), \mathrm{D}_{\mathrm{j}}$ is found to be equal to $9 \times 10^{-16} \mathrm{~cm}^{2} \mathrm{~s}^{-1}$ and to $2.8 \times 10^{-14} \mathrm{~cm}^{2} \mathrm{~s}^{-1}$ at $650{ }^{\circ} \mathrm{C}$, respectively. The two dimensional $\mathrm{B}$ distribution at the end of the simulation corresponding to the profile shown on Fig. 2 is presented on Fig. 3. The diffusion regime of type $B$ is clearly evidenced. While the in-grain diffusion is significantly lower than the diffusion in the grain boundary, it is enough for the grain to act as a reservoir of B atoms for fast diffusion in the boundary. 
Phosphorus uphill Diffusion. For annealing temperatures up to $650{ }^{\circ} \mathrm{C}$, the $\mathrm{P}$ composition stays the same as after LPCVD deposition. It is quite homogeneous in the entire Si layer. The crystallization of the layer as well as the redistribution of $\mathrm{B}$ do not influence the $\mathrm{P}$ distribution during annealing. However, for temperatures as high as $755^{\circ} \mathrm{C}$, the $\mathrm{P}$ atoms are found to diffuse. As the original $\mathrm{P}$ distribution was homogenous, the driving force for the $\mathrm{P}$ diffusion is obviously not the usual concentration gradient. Figure 4 presents the normalized SIMS profiles of $\mathrm{B}$ and $\mathrm{P}$ in the same sample, after annealing at $800{ }^{\circ} \mathrm{C}$ for 5 hours. One can see that the $\mathrm{P}$ atoms gather where the concentration of $\mathrm{B}$ is the highest. Furthermore, the profile of $\mathrm{B}$ as well as the profile of $\mathrm{P}$ can be divided into the three same zones (I, II and III) corresponding to three different composition levels versus depth, showing the direct relation between $\mathrm{P}$ diffusion and $\mathrm{B}$ concentration. The interactions between $\mathrm{P}$ and $\mathrm{B}$ atoms can be of two types. First, B and $\mathrm{P}$ are chemically attracted atoms as these two elements are known to form binary compounds [14]. Furthermore, both of them are also forming binary compounds with Si [14]. Secondly, when the dopants are activated in the Si crystal, they are ionized. As $\mathrm{B}$ is a $p$-type dopant and $\mathrm{P}$ is a $n$-type dopant, attractive electrostatic interactions can exist between the two species. Figure 5 presents the concentration profile of $\mathrm{P}$ versus depth after implantation as well as after annealing at $755^{\circ} \mathrm{C}$ for $4 \mathrm{~h}$ and at $800{ }^{\circ} \mathrm{C}$ for $5 \mathrm{~h}$. During annealing the P concentration gradually decreases in the zones II and III, while it increases in zone I. The concentration profiles of $\mathrm{B}$ after annealing at $755^{\circ} \mathrm{C}$ for $4 \mathrm{~h}$ and at $800{ }^{\circ} \mathrm{C}$ for $5 \mathrm{~h}$ are reported in figure 6 . Figures 5 and 6 suggest that at high temperature the diffusion of $\mathrm{P}$ can occur

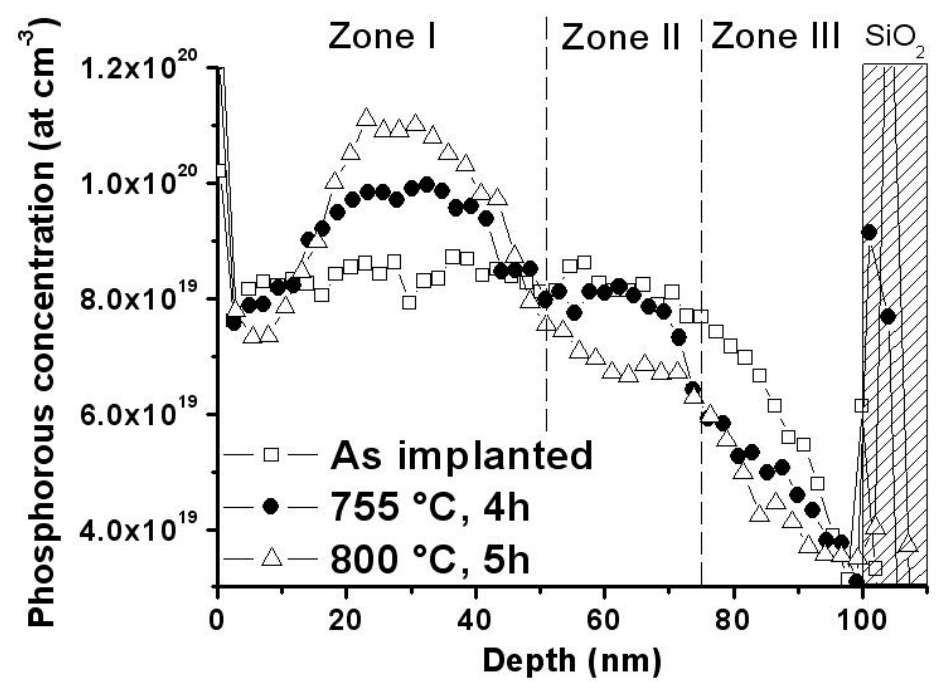

Fig. 5. $\mathrm{P}$ concentration profiles measured by SIMS after implantation (O); after implantation and annealing at $755^{\circ} \mathrm{C}$ for $4 \mathrm{~h}\left(\right.$,) and at $800{ }^{\circ} \mathrm{C}$ for $5 \mathrm{~h}(8)$.

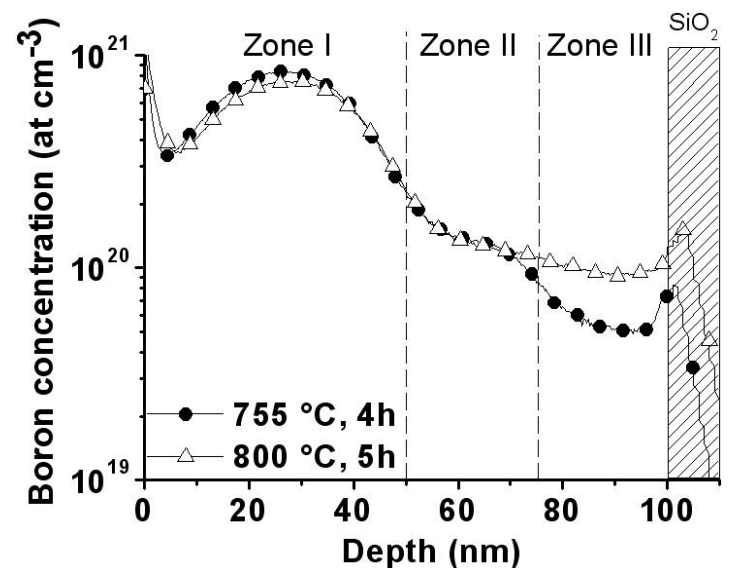

Fig. 6. B concentration profiles measured by SIMS after annealing at $755^{\circ} \mathrm{C}$ for $4 \mathrm{~h}($,$) and$ at $800{ }^{\circ} \mathrm{C}$ for $5 \mathrm{~h}(8)$.

simultaneously with the diffusion of B. One can note that after annealing at $800{ }^{\circ} \mathrm{C}$ for $5 \mathrm{~h}$ the B concentration is the same in zone II and is higher in zone III compared to after annealing at $755^{\circ} \mathrm{C}$ for $4 \mathrm{~h}$, while the concentration of $\mathrm{P}$ is lower in the same zones on the profile measured at $800{ }^{\circ} \mathrm{C}$. Thus two contradictory phenomena are observed: $\mathrm{P}$ diffuses to the zone the most concentrated in $\mathrm{B}$ (zone I), but at the same time the P composition decreases in the zones II and III even though the concentration of $\mathrm{B}$ increases. The principal difference between zone I and the two others is that the $\mathrm{B}$ concentration is higher than the solubility limit and that some B clusters are probably present in zone I. Because of the chemical interactions between the three species and the high level of concentration of both $\mathrm{B}$ and $\mathrm{P}$ atoms, the lack of diffusion of $\mathrm{B}$ atoms in zone I could be actually due to the formation of binary or ternary precipitates and/or clusters. Thus it seems plausible that the chemical interactions between $\mathrm{B}$ and $\mathrm{P}$ atoms occur only in zone I and that no interactions are observed in zones II and III, where the B concentration is lower than the solubility limit. Moreover, dopants are active only if they are located on substitutional sites in the Si crystal. In this case they are also mobile (they can diffuse) and correspond to concentrations lower than the solubility limit. Figs. 1, 2 and 3 show that in zones II and III the concentration of B atoms in the grains is lower than 
the solubility limit. In consequence, the electrostatic interactions between $\mathrm{B}$ and $\mathrm{P}$ ionized atoms should be observed in these zones. Furthermore, if B clusters are formed in zone I, then the concentration of active $\mathrm{B}$ atoms should be almost the same in the entire zone, and mainly equal to the solubility limit of B in c-Si. After annealing at $800{ }^{\circ} \mathrm{C}$ for $5 \mathrm{~h}$, the B concentration in zones II and III is also close to the solubility limit (Figs. 1 and 6). Thus it is difficult to explain why the ionized $\mathrm{P}$ atoms would be attracted by activated $\mathrm{B}$ atoms only in zone I. These observations support thus the idea that in our experiments the $\mathrm{P}$ diffusion is driven by the formation of a compound or clusters in zone I (chemical interaction between B, P and Si).

\section{Summary}

The redistribution of $\mathrm{B}$ during the crystallization of a homogeneously $\mathrm{P}$ doped a-Si layer has been investigated. $\mathrm{B}$ atoms are redistributed only for concentrations lower than $2 \times 10^{20} \mathrm{at} \mathrm{cm}^{-3}$. The crystallization process leads to a non "Fickian" redistribution, which may be due to B diffusion in a-Si and/or to a partition mechanism due to the difference of B solubility in a-Si and c-Si. After the entire crystallization of the layer, $\mathrm{B}$ atoms diffuse through the layer in the type $B$ regime with a coefficient which is in agreement with the $\mathrm{B}$ diffusion coefficient given in the literature for diffusion in poly-Si. Although $\mathrm{P}$ is immobile for temperatures up to $650{ }^{\circ} \mathrm{C}$, for temperatures as high as $755^{\circ} \mathrm{C}$, it is found to diffuse towards the region with the highest $\mathrm{B}$ concentration, where the main part of $\mathrm{B}$ atoms are immobile during annealing. The attraction between $\mathrm{B}$ and $\mathrm{P}$ atoms is interpreted as being due to chemical interactions (compound formation).

\section{References}

[1] International Technology Roadmap for Semiconductors, http://public.itrs.net (2003).

[2] J.M. Jacques, L.S. Robertson, K.S. Jones: Appl. Phys. Lett. Vol. 82 (2003), p. 3469

[3] R. Duffy, V.C. Venezia, A. Heringa, T.W.T. Husken, M.J.P. Hopstaken, N.E.B Cowern, P.B. Griffin, C.C. Wang: Appl. Phys. Lett. Vol. 82 (2003), p. 3647

[4] R. Duffy, V.C. Venezia, A. Heringa, B.J. Pawlak, M.J.P. Hopstaken, G.C.J Maas, Y. Tamminga, T. Dao, F. Roozeboom, L. Pelaz: Appl. Phys. Lett. Vol. 84 (2004), p. 4283

[5] T.I. Kamins, J. Manoliu, R.N. Tucker and Tucker: J. Appl. Phys. Vol. 43 (1972), p. 83

[6] K. Sakamoto, K. Nishi, T. Yamaji, T. Miyoshi and S. Ushio: J. Electrochem. Soc. Vol. 132 (1985), p. 2457

[7] P. Pichler: Mat. Res. Soc. Symp. Proc. Vol. 717 (2002), p. 103

[8] S. Solmi, E. Landi, F. Baruffaldi: J. Appl. Phys. Vol. 68 (1990), p. 3250

[9] P.C. Zalm, C.J. Vriezema: Nucl. Instrum. Methods B Vol. 67 (1992), p. 495

[10] C.E. Allen, D.L. Beke, H. Bracht, C.M. Bruff, M.B. Dutt, G. Erdélyi, P. Gas, F.M. d'Heurle, G.E. Murch, E.G. Seebauer, B.L. Sharma, N.A. Stolwijk: Diffusion in Semiconductors and NonMetallic Solids (Landolt-Börnstein Vol. III/33A, Springer-Verlag, Germany 1998).

[11] J.C. Fisher: J. Appl. Phys. Vol. 22 (1951), p. 74

[12] R.B. Fair: Concentration profiles of diffused dopants in silicon: Impurity Doping Processes in Silicon (edited by F. Wang, North Holland 1981), p. 135

[13] J.S. Christensen, H.H. Radamson, A.Yu. Kuznetsov and B.G. Svensson: Appl. Phys. Lett. Vol. 82 (2003), p. 2254

[14] Binary Alloy Phase Diagrams (ASM International, 1996). 